\title{
Anterior Cardinal Vein
}

National Cancer Institute

\section{Source}

National Cancer Institute. Anterior Cardinal Vein. NCI Thesaurus. Code C34108.

A vein that drains blood from the cranium into the common cardinal vein during embryonic development. 